

\section{Transforming Used Palm Oil into Biogasoline Investigation of Activity and Selectivity of Mesoporous Silica Catalyst for Hydrocracking Process}

\author{
Ahmad Suseno \\ Universitas Diponegoro \\ Karna Wijaya ( $\nabla$ karnawijaya@ugm.ac.id) \\ Universitas Gadjah Mada \\ Eddy Heraldy \\ Universitas Sebelas Maret \\ Lukman Hakim \\ Brawijaya University: Universitas Brawijaya \\ Wahyu Dita Saputri \\ LIPI: Lembaga Ilmu Pengetahuan Indonesia
}

\section{Original Research}

Keywords: mesoporous silica, hydrocracking, used palm oil, biogasoline

Posted Date: February 9th, 2021

DOI: https://doi.org/10.21203/rs.3.rs-166904/v1

License: (c) (1) This work is licensed under a Creative Commons Attribution 4.0 International License.

Read Full License 


\section{Abstract}

Research on mesoporous silica synthesis using CTAB template as well as its activity and selectivity in the hydrocracking of used palm oil has been conducted. This research was initiated with the synthesis of mesoporous silica material by varying the TEOS to CTAB ratios at 2:1, 4:1, and 8:1, later calcined at varying temperatures of 300,350 , and $400^{\circ} \mathrm{C}$. The products were characterized by XRD, SEM-EDX, and GSA. The hydrocracking was performed with a feed ratio of $1: 100$ and $\mathrm{H}_{2}$ gas flow rate of $20 \mathrm{~mL} / \mathrm{min}$ for 1 hour. The results showed that the highest activity of mesoporous silica was found in the TEOS:CTAB ratio of 8:1 and calcination temperature of $500{ }^{\circ} \mathrm{C}$. The mesoporous silica produced had higher crystallinity, higher percentages of $\mathrm{Si}$, and larger pore size. The catalyst activity test showed that the application of mesoporous silica increased the amount of biogasoline fraction $\left(\mathrm{C}_{5}-\mathrm{C}_{12}\right)$ produced at the optimum temperature condition of $350^{\circ} \mathrm{C}$ using the MCT81-500 catalyst.

\section{Introduction}

Mesoporous silica nanoparticle has attracted increasing attention for their various applications in things such as separations [1], catalysis [2, 3], chemical sensing [4], and biomedicine [5-7]. Mesoporous silica exhibiting different forms or morphologies, including sphere, film, monolith, rod, fiber, have been synthesized in many earlier studies [8-17]. They are particularly important as they feature promising functions for catalyst, separation, electronic, optical, and electrochemical applications [18-22]. The development of nanostructured materials has become a growing fascination in recent years in their various fields of application, including catalysis and adsorption. Thermal and hydrothermal stability are important parameters that must be taken into account when designing the right material for the application of heterogeneous catalytic chemical reactions. The type of heterogeneous catalyst currently under study is the silica-based catalyst. This type of catalyst has several superior properties such as high thermal and chemical resistance, reactive surface and easily modified acidity [23-24].

The nature of the silica is primarily determined by the parameters of the synthesis process, such as $\mathrm{pH}$, calcination temperature, and manufacturing process [25-26]. On the other hand, the reactivity of the silica used in hydrocracking is mostly still too low and must be increased. One modification that can be created in this matter is to form meso-sized pores within the silica structure. Pores are deemed mesosized when they have pore sizes of 2 to $50 \mathrm{~nm}$ [27]. Materials with mesoporous size are promising for hydrocracking processes because of their large surface area, thermal, chemical and mechanical stability, regular pore distribution, and high adsorption capacity [28-29]. The manufacturing process of mesoporous silica normally involves an approach that uses a mold for pore formation. The type of template and the ratio of precursors being used are decisive of the sizes, and distributions in the materials made [30-31]. The present study addresses the use of the CTAB template and analyzes the properties of the mesoporous silica resulting from the use of this template. This study also presents the analysis of its activity and selectivity in the hydrocracking of used palm oil. 


\section{Materials And Methods \\ 2.1. Materials}

Tetraethyl orthosilicate/TEOS, $\mathrm{NaOH}, \mathrm{NH}_{4} \mathrm{OH}$ were purchased from E. Merck. Nitrogen and hydrogen gases from PT. Samator Gas (Semarang, Central Java). Palm oil was obtained from a traditional market in Semarang, Central Java.

\subsection{Methods}

\subsubsection{Preparation}

The hierarchical mesoporous silica synthesis was carried out by mixing 0.8018 gram of CTAB (template) and $4 \mathrm{ml} ; 2 \mathrm{~mL}$ and $1 \mathrm{~mL}$ of TEOS. The mixtures were stirred for 15 minutes, and each was added with 5 $\mathrm{ml}$ of a $2 \mathrm{M} \mathrm{NaOH}$ solution, dropwise, followed by another stirring for 3 hours at $80^{\circ} \mathrm{C}$. The solid obtained was filtered and washed with distilled water at a neutral $\mathrm{pH}$. The drying process was carried out at a temperature of $150^{\circ} \mathrm{C}$ for 2 hours and continued refining and sieving at 200 mesh. The $4 \mathrm{ml}, 2 \mathrm{~mL}$, and 1 $\mathrm{mL}$ TEOS product variations were labeled MCT41-500; MCT21-500, and MCT11-500. The last step of the synthesis was the calcination process of each sample at $500^{\circ} \mathrm{C}$ for 4 hours.

\subsubsection{Characterization}

Scanning electron microscope (SEM) images were taken using with a Phenom proX G6 desktop SEM. The X-ray diffraction (XRD) pattern of the mesoporous silica was measured using a X'Pert3 Powder X-ray Diffractometer from Malvern Panalytical in continuous scan mode with a scan range of $1-10^{\circ}$ and a scan-interval of $0.02^{\circ}$. Other analyses involved FT-IR (PerkinElmer Spectrum 100), Gas sorption analyzers (GSA-Quantachrome Nova 1200e), and Gas Chromatography-Mass Spectrometry (GC-MS GC-2010 Shimadzu).

\subsubsection{Catalytic Activity}

The palm oil hydrocracking process using the mesoporous silica catalyst produced was carried out with 3 temperature variations, namely 300,350 , and $400^{\circ} \mathrm{C}$ and $\mathrm{H}_{2}$ gas flow rate of $20 \mathrm{ml} /$ minute for 1 hour.

\section{Results And Discussion}

The infrared spectra of the silica mesoporous material (MCT81-500) are presented in Fig. 1. The values of the wavenumber that appeared were $470,794-802,956-964,1095-1103,1635$, and $3448-3464 \mathrm{~cm}^{-}$ 1 , each one displayed the absorption of the bending vibrations of Si-O-Si, symmetric Si-O-Si stretching vibrations, $\mathrm{Si}-\mathrm{OH}$ stretching vibrations, asymmetric Si-O-Si stretching vibrations, $\mathrm{H}-\mathrm{O}-\mathrm{H}$ bending vibrations and $\mathrm{O}-\mathrm{H}$ stretching vibrations. However, this characterization was not sufficient to illustrate the crystallinity of the material. The vibration bands of ammonia adsorption that appear in the IR region of $1387.82 \mathrm{~cm}^{-1}$ was indicative of Lewis acid. The IR bands at $1450-1455 \mathrm{~cm}^{-1}$ are characteristic of the 
Lewis acid sites, and $1490 \mathrm{~cm}^{-1}$ indicated the combined presence of all acid sites. There was an absence of a band at 1450-1455 $\mathrm{cm}^{-1}$, which is characteristic of Lewis acid, though peaks at 1640 and $1540 \mathrm{~cm}^{-1}$ were observed corresponding to Broønsted acid sites. The peaks that emerged in the wavenumbers of $3465.53 \mathrm{~cm}^{-1}$ or $3434.02 \mathrm{~cm}^{-1}$ identified the $-\mathrm{OH}$ band stretching vibration of water molecules. This analysis was done to perceive the absorptions produced by the mesoporous silica synthesized and remark the changes in the absorptions due to the use of CTAB. Figure 1 presents the spectra of the sample made.

XRD characterization was performed to determine the crystallinity of the catalyst. The diffractograms of the catalyst materials are displayed at $2 \theta=2-15^{\circ}$.

The diffractograms of the hierarchical mesoporous silica materials with various TEOS and CTMA ratios are shown in Fig. 2. Based on intensities, the diffractograms above showed that the MCT81-500 or 8:1 sample produced the highest degree of crystallinity. The diffractogram of all the samples after calcination showed a peak indexable at (100), at $2 \theta$ angles of $2.61^{\circ} ; 3.02^{\circ}$ and $2.67^{\circ}$ for the MCT21-500, MCT41-500 and MCT81-500 samples, respectively. The intensity of the peaks increased with increasing silica content or TEOS/matrix ratio. These results reflected that precursor and surfactant compositions significantly affect the morphology and crystallinity of the mesoporous silica produced. These results also indicate whether the addition of the appropriate matrix can increase the intensity of the silica crystallinity based on the SEM analysis.

SEM characterization was performed to determine the topography of the surface and the morphology of the catalyst, while the EDX characterization was used to determine the composition of the elements on the surface of the catalyst. The SEM images are shown in Fig. 3.

The SEM images illustrated that the mesoporous silica had different crystallinities depending on the ratio of TEOS to the template. The results showed that the hierarchical mesoporous silica synthesis with the 8:1 ratio had a structure with the highest crystallinity. The results of the elemental analysis with EDX in Table 1 inferred that higher crystallinity corresponded to increased silicate content.

Table 1

Results of element analysis with EDX

\begin{tabular}{|lllll|}
\hline Sample & \multicolumn{4}{l}{ Content (\%) } \\
& Si & O & N & C \\
\hline MCT81-500 & 45.31 & 41.11 & 6.02 & 7.75 \\
\hline MCT41-500 & 35.76 & 55.83 & 8.41 & - \\
\hline MCT21-500 & 27.50 & 64.24 & 8.26 & - \\
\hline
\end{tabular}

Based on the SEM images, differences in surface morphologies and crystallinities were not uniform (heterogeneous). Variations in the TEOS/template ratio would affect many properties such as surface 
area, pore size, and morphology. Furthermore, as can be seen from Fig. 3 (a), (b), and (c), the surface morphologies of the silica samples tended to be round, whereby most particles tended to form bonds or pieces of large round particles commonly called agglomeration. The SEM results also inferred that higher crystallinity is coherent with a higher concentration of silica. In the EDX analysis, the presence of elements of carbon (C), oxygen (O), Nitrogen (N), and silica (Si) was indicated. Specifically, the Si and $\mathrm{O}$ indicated the formation of siloxane (Si-O-Si) and silanol ( $\mathrm{Si}-\mathrm{OH})$ groups in addition to the appearance of a special carbon content in the SCM81-500 material presented by the XRD peak $\left(2 \nabla=2.61^{\circ}\right)$ shown in Fig. 2. GSA characterization was performed to determine the specific surface area, total pore volume, average diameter, and pore distribution of the catalysts. The specific surface area, the average pore diameter and the total pore volume of the catalysts are listed in Table 2.

Table 2

Pore properties of the mesoporous silica catalysts

\begin{tabular}{|llll|}
\hline Sample & $\begin{array}{l}\text { Specific Surface Area } \\
\left(\mathbf{m}^{2} \mathbf{g}^{-1}\right)\end{array}$ & $\begin{array}{l}\text { Total Pore Volume } \\
\left(\mathbf{c} \mathbf{~ g ~}^{-1}\right)\end{array}$ & Average Pore Diameter $(\mathbf{n m})$ \\
\hline МСТ81-500 & 292.294 & 0.040 & 31.912 \\
\hline МСT41-500 & 382.514 & 0.199 & 31.892 \\
\hline МСT21-500 & 324.254 & 0.109 & 31.484 \\
\hline
\end{tabular}

The results of the GSA analysis showed that the MCT81-500 sample had a higher average pore radius than the other samples. This showed that the addition of smaller CTAB proportion, particularly at a ratio of 8:1 of TEOS precursor (silicon) to the template, can manifest larger-radius porous silica. Though, other parameters such as the total pore volume and the specific surface area of the MCT81-500 catalyst were lower. The isothermal curves of the samples are shown in Fig. 4.

From Fig. 5, the materials were shown to had had type IV adsorption isotherms. According to Sing et al. (1985), type IV isothermal pattern has four types of hysteresis loops that indicate the mesoporous character of the pore dimensions intrinsic to a material. To perceive the state of the pores more detail, it was necessary to analyze the distribution curves of the pores in the materials. Data in regards to pore radius distributions are shown in Fig. 5. The data displayed similar pore distributions and a mesoporous sensitivity range $(2-50 \mathrm{~nm})$ of the materials.

According to GCMS analysis of the liquid products from the hydrocracking process, the major products that materialized from the cracking process were gasoline $\left(C_{5}-C_{15}\right)$, diesel $\left(C_{16}-C_{18}\right)$, and wax $\left(>C_{18}\right)$ fractions. The analysis of the compositions of the products from different cracking processes is presented in Fig. 6 below.

The thermal cracking performed showed that the gasoline fraction obtained was relatively low. The percentage of products with the use of the mesoporous silica catalyst at $350^{\circ} \mathrm{C}$ showed an increase in gasoline fraction products inherent with increasing crystallinity and a decrease in the number of matrices 
in the synthesis of these materials. The results of this study indicated that the use of MCT81-500 catalyst with a catalyst/feed ratio of $1: 100, \mathrm{H}_{2}$ gas flow of $20 \mathrm{ml} / \mathrm{min}$, and a hydrocracking duration of 1 hour comprise the optimal conditions to produce the best gasoline fraction.

\section{Conclusion}

The use of CTAB as a matrix in the manufacture of mesoporous silica has been successfully carried out, as evidenced by the crystallinity and the increased size distribution of the silica pores in the meso dimension. The best performing mesoporous silica was the MCT81-500 catalyst with a TEOS: matrix ratio of $8: 1$. The catalyst activity test showed that the use of mesoporous silica increased the amount of gasoline fraction product $\left(\mathrm{C}_{5}-\mathrm{C}_{12}\right)$.

\section{Declarations}

\section{Author Contribution}

All authors have contributed equally

\section{Acknowledgment}

The authors wish to thank the Diponegoro University Citation Improvement Program for 2019 with the contract number 205-02 /UN7.P4.3/PP/2019 for the financial support provided. as well as collaborators from Indonesia-10 of PTNBH, UGM, UB and UNS (PPKI Project 2019).

\section{References}

1. Sarvi MN, Bee TB, Gooi CK et al (2014) Chem Eng J 235:244-251

2. Sheng W, Wei W, Li JJ et al (2016) Appl Surf Sci 387:1116-1124

3. Tao Y, Ju EG, Ren JS, Qu XG (2015) Adv Mater 27:1097-1104

4. Lee YC, Dutta S, Wu KC-W (2014) Chem Sus Chem 7:3241-3246

5. Tan SY, Teh C, Ang CY et al (2017) Nanoscale 9:2253-2261

6. Wang Y, Gu HC (2015) Adv Mater 27:576-585

7. Gao WX, Hu YL, Xu L et al., Chin Chem Lett (2018), https://doi.org/10.1016/j.cclet.2018.05.022

8. Lai SM, Lai HY, Chou MY (2014) Micropor Mesopor Mat 196:31-40

9. Hikosaka R, Nagata F, Tomita M, Kato K (2016) Colloids Surf B 140:262-268

10. Ng TN, Chenac XQ, Yeung KL (2011) RSC Adv 5:13331-13340

11. Knežević N, Durand JO (2015) Nanoscale 7:2199-2209

12. Wei J, Sun ZK, Luo W et al (2017) J Am Chem Soc 139:1706-1713 
13. Wang XQ, Zhang Y, Luo W et al (2016) Chem Mater 28:2356-2362

14. Gu D, Bongard H, Meng $Y$ et al (2010) Chem Mater 22:4828-4833

15. Luo W, Zhao T, Li YH et al (2016) J Am Chem Soc 138:12586-12595

16. Yuan KP, Che RC, Cao Q et al (2015) ACS Appl Mater Inter 7:5312-5319

17. Liu Y, Deng YH, Sun ZK et al (2013) Small 9:2702-2708

18. Teng ZG, Zheng GF, Dou YQ et al (2012) Angew Chem Int Ed 51:2173-2177

19. Nasir T, Herzog G, Hebrant M et al (2018) ACS Sens 3:484-493

20. Guo SJ, Wang ZW, Xu ZY et al (2017) Chin Chem Lett 28:2143-2146

21. Shen DK, Wang G, Liu ZC et al (2018) J Am Chem Soc 140:11402-11407

22. Liu YP, Shen DK, Chen G et al (2017) Adv Mater 29:1702274-1702274

23. Kamitori Y, Hojo M, Masuda R, Izumi T, Tsukamoto S (1984) JOrg Chem 49:4161-4165

24. Williams S, Neumann A, Bremer I, Su Y, Drager G, Kasper C, Behrens P (2014) J Mater Sci: Mater Med $26: 1-16$

25. Coltrain BK, Melpolder SM, Salva JM (1992) John Wiley \& Sons Inc. New York

26. Schmidt H (1988) J 100 (:51-64 N Solids, )

27. Huo Q, Margolese DI, Stucky GD (1996) Chem Mater 8:1147-1160

28. Lai CY, Thermodyn Catal J, 5(2013) (1), 1-3

29. Munir D, Usman MR, 2016, 14th (2016) Int. Sym. on Advanced Materials, Islamabad

30. Taguchi A, and Schuth F (2005) Microporous Mesoporous Mater 77(:1-45, )

31. Vartuli JC, Schmitt KD, Kresge CT, Roth WJ, Leonowicz ME, McCullen SB, Hellring SD, Beck JS, Schlenker JL, Olson DH, and Sheppard EW (1994) (Proceedings of the 10th International Zeolite Conference, GarmischPartenkirchen, Germany

\section{Figures}




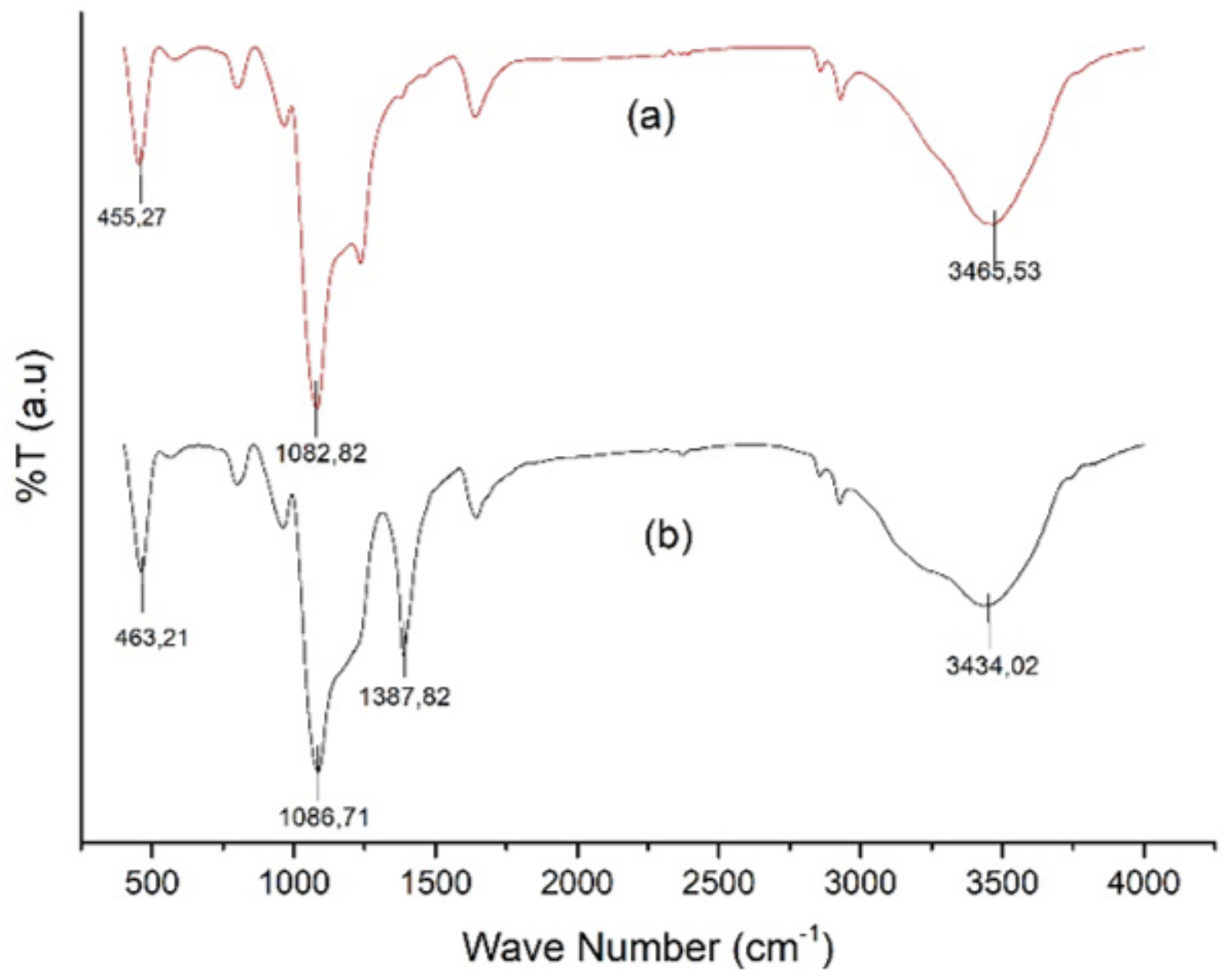

Figure 1

FTIR Spectra of MCT81-500: (a) Before (b) After adsorption ammonia 




Figure 2

XRD patterns of the mesoporous silica materials

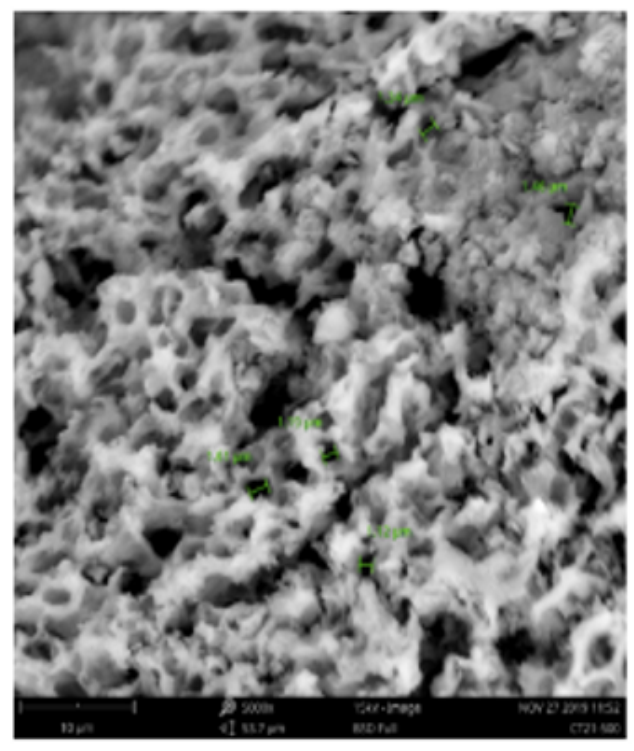

(a)



(b)

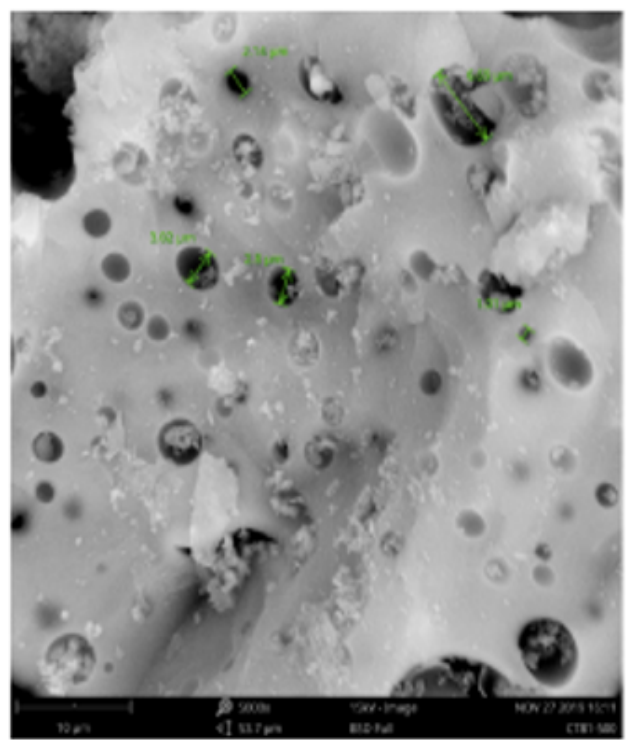

(c)

Figure 3 
SEM images of (a) MCT21-500 (b) MCT41-500 (c) MCT81-500

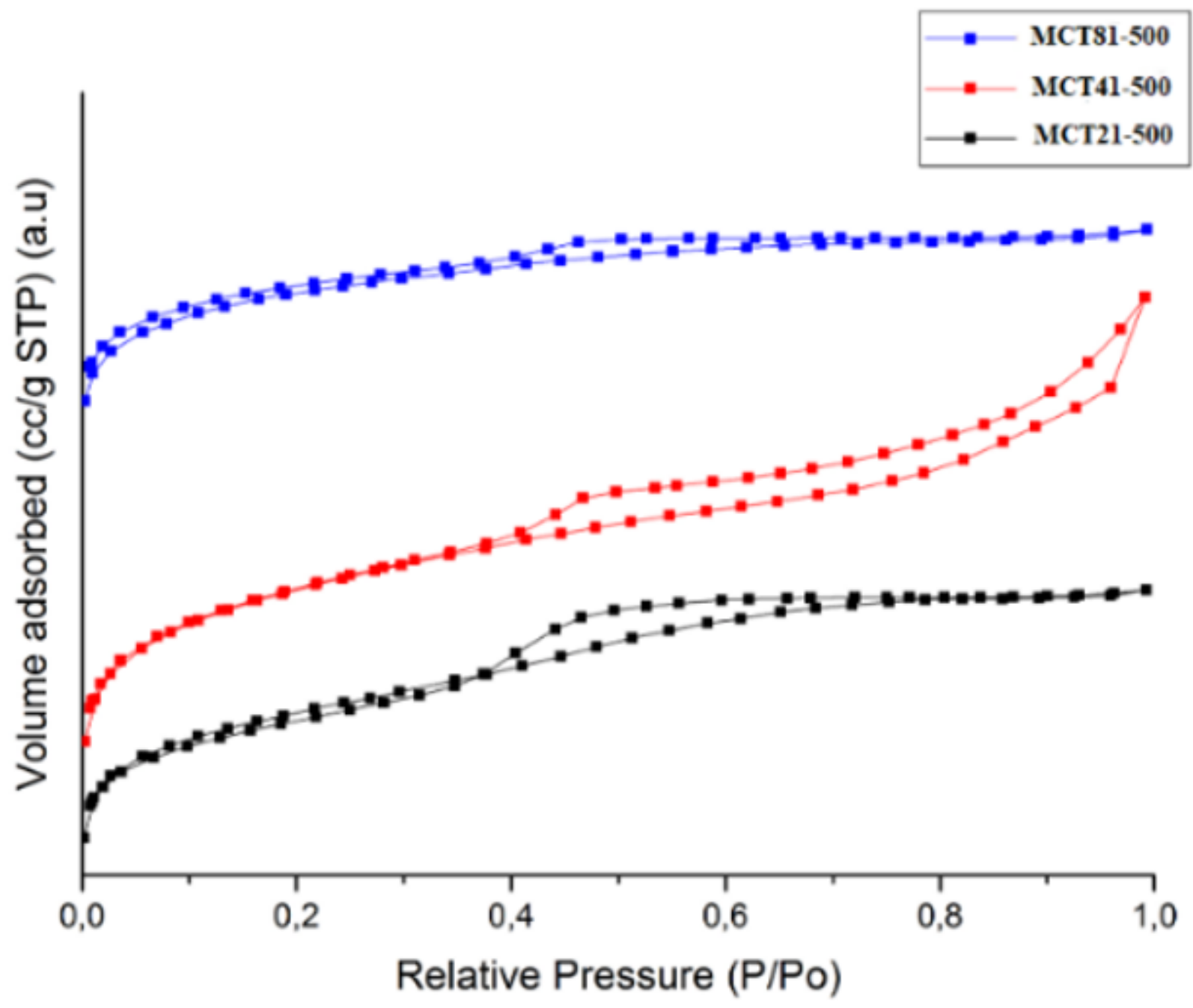

Figure 4

Adsorption isotherm curves the mesoporous silica materials 


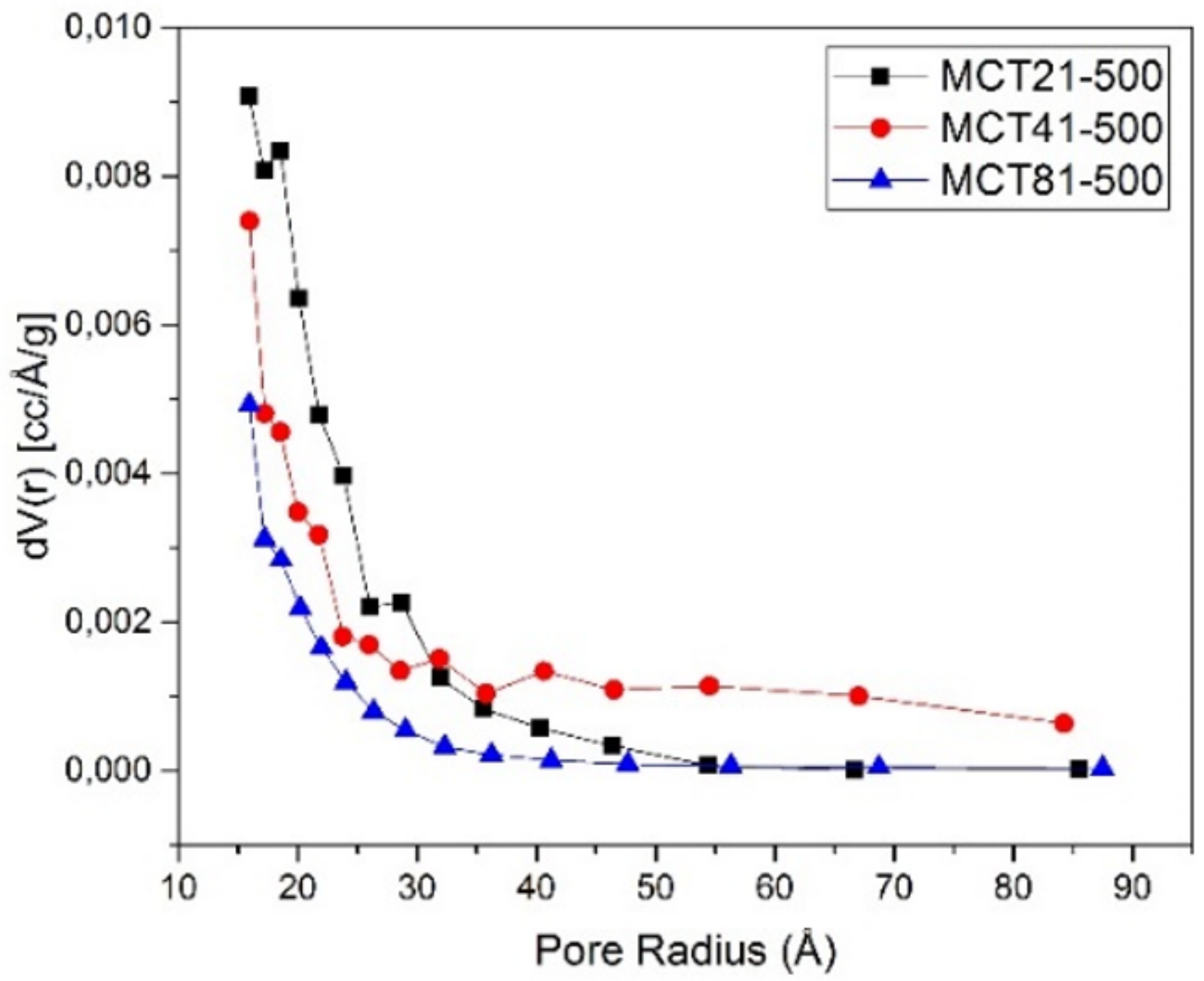

Figure 5

Pore radius size distribution of the mesoporous silica materials 


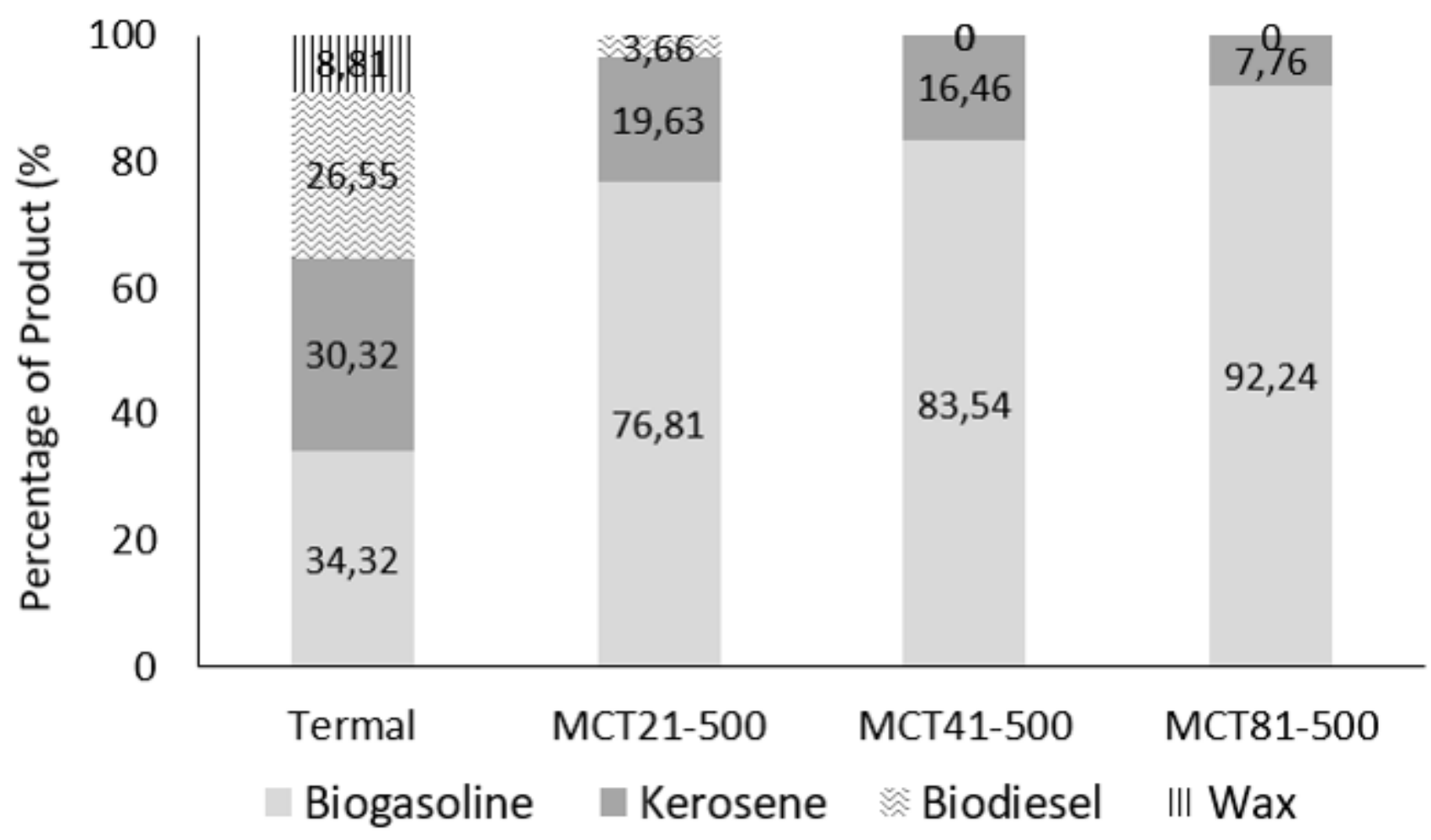

Figure 6

Product fraction percentages produced from the hydrocracking process using various catalysts 